\title{
¿Es el escribir un diario un fármacon?'
}

\author{
LUIS BRANDA \\ McMaster University \\ Canadá \\ brandal@mcmaster.ca
}

Is Writing a Diary a Pharmakon?

(Recibido: I8-I2-20I6; aceptado: 24-I2-2OI6)

Resumen. Tras un prolongado intercambio epistolar entre dos docentes universitarios (Branda, 2015; 2016), la relación afectuosa ha sido terminada por una de los correspondientes. En este escrito se presentan las entradas en el diario de Alberto, el otro correspondiente, donde se incluyen reflexiones relacionadas a Henri-Frédéric Amiel y referencias a los comentarios sobre su psicología que la lectura de su Journal intime ha generado en varios escritores, incluyendo Gregorio Marañón. También se menciona un aspecto de la vida de Amiel que parece haber recibido menos atención, que es su rol como docente. El diario finaliza con comentarios sobre las aspiraciones del diarista con reflexiones sobre el pasado y la incertidumbre del futuro.

Palabras clave: Amiel; Bopp; crítica; de Weck; docencia; Marañón; Sand.
Abstract. Following a lengthy epistolary exchange between two university professors (Branda, 2015; 2016), one of the correspondents has ended their affectionate relationship. This work shows the diary entries of Alberto, the other correspondent, including reflexions related to Henry-Frédéric Amiel. References are made to the psychological interpretations generated by various authors-including Gregorio Marañón-by the reading of his Journal intime. There is also mention of an aspect of Amiel's life that has not been the subject of detailed analysis: his role as a teacher. The diary presented here ends with comments about the aspirations of the diarist, reflexions about the past, and the uncertainty of the future.

Key words: Amiel; Bopp; Criticism; de Weck; Marañón; Sand;Teaching.

\footnotetext{
I Para citar este artículo: Branda, Luis (20I7). ¿Es el escribir un diario un fármacon? Álabe 15. [www.revistaalabe.com] DOI: IO.I5645/Alabe2OI7.I5.II
} 
On doit s'en souvenir, et Platon nous y invite, quand l'écriture est proposée comme pharmakon. Contraire a la vie, l'écriture - on, si l'on veut, le pharmakon - ne fait que déplacer voire irriter le mal. Sous prétexte de suppléer la mémoire, l'écriture rend encore plus oublieux; loin d'accroître le savoir, elle le réduit. Elle ne répond pas au besoin de la mémoire, vise à côté, ne consolide pas la mnèmè, seulement l'hypomnesis. Elle agit donc bien comme tout pharmakon.

Jacques Derrida. La pharmacie de Platon.

Última semana de marzo.

Como docente en la universidad aparentemente gozo de gran libertad, pero "Je ne suis pas libre, car je n'ai pas la force d'exécuter ma volonté" (Amiel, I949: 39). Habiendo comenzado mi carrera profesional y docente en una institución que aún se encuentra en el proceso de establecerse, lo cual no acrecienta mi currículum vítae, la única seguridad que poseo es seguir trabajando en ella. No me siento autónomo sino aprisionado y, como lo hizo Madame Roland durante su encarcelamiento, he establecido una rutina diaria para desarrollar la disciplina liberadora de mi mente. Imitándola, comienzo a escribir este diario; es mejor llamarlo un cuaderno de notas. Dado que deseo registrar observaciones y reflexiones, muchas que surgen de mis lecturas la fecha precisa no es importante. Lo que deseo registrar no es lo rutinario y monótono de mi vida porque si no mi diario sería evocativo del famoso Diary of a nobody de los hermanos George y Weedon Grossmith. Solo alguien como Amiel tiene la habilidad de registrar lo nimio y hacerlo interesante para el lector. Creo que correctamente, Marañón llama al diario de Amiel un "documento de auténtica humanidad" y dice que es esa ventana anónima de la calle estrecha que un visitante a una ciudad accidentalmente encuentra, "ventana estrecha que nos enseña un interior mediocre, pero lleno de sentido profundamente humano, de glorias y bostezos de calibre vulgar, y, por lo tanto, iguales a los nuestros" (Marañón, ı932: 6).

La primavera ha comenzado con sus días nebulosos.

Ah ! que le printemps est redoutable pour les solitaires. Tous les besoins endormis se réveillent, toutes les douleurs disparues renaissent, le vieil homme terrasséet bâillonnése relève et se met à gémir. Les cicatrices redeviennent blessures saignantes et ces blessures se lamentent à qui mieux mieux. (Amiel, I949 : 234).

Bajo el palio de la soledad trato de encontrar maneras de poder resignarme a su ausencia. Debo superar este trance áspero de mi vida; Marañón dijo que uno de los trances más ásperos es el de amar (Marañón, I932: 99). Causándome un dolor nostálgico resuena en mi mente lo que George Sand le escribió a su futura nuera, Lina Calamatta, 
el 3I de marzo de I862: "Fiez-vous à nous, fie-toi à lui, et crois au bonheur. Il n'y en a qu'un dans la vie, c'est d'aimer et d'être aimée." (Sand, G. 1883:324). Y finaliza: "A bientôt, j'espère! J'espère et je désire et je veux. "Pensando en Ella no me ha consolado leer lo que Amiel le escribió a Charles Dollfus, el director de la Revue germanique: "Les femmes trop exceptionnelles ne donnent pas le bonheur. Les prodiges son pour la montre non pour l'usage."(Amiel, 2006: 295).

Sé que emocionalmente aún estoy en un proceso de maduración, pero a diferencia de lo que pasa con las frutas me estoy endureciendo. Juan Gabriel Vásquez ha escrito, La edad adulta trae consigo la ilusión perniciosa del control, y acaso dependa de ella. Quiero decir que es ese espejismo de dominio sobre nuestra propia vida lo que nos permite sentirnos adultos, pues asociamos la adultez con la autonomía el soberano derecho a determinar lo que va a sucedernos enseguida. El desengaño viene más pronto o más tarde, pero viene siempre no falta a la cita, nunca lo ha hecho. Cuando llega lo recibimos sin demasiada sorpresa, pues nadie que viva lo suficiente puede sorprenderse de que su biografía haya sido moldeada por eventos lejanos, por voluntades ajenas, con poca a ninguna participación de sus propias decisiones. (Vásquez, 2OII: 2I3).

Primera semana de abril.

En mi estadía en Paris durante las fiestas de Pascua me alojé en el Hôtel Lutetia donde estuve hace un año con Ella; el maître d'hôtel sigue siendo Camille Blanche, quien sorprendentemente, me recordó y con delicada cautela no preguntó por Ella. En mi recorrida por las librerías de la Rue de Seine, encontré en la Librairie Camille Sourget una copia del libro que Léon Bopp escribió sobre Amiel (Bopp, I926). El libro es básicamente su tesis doctoral hecha en La Sorbona, --dedicada a su "cher maître en témoignage de gratitude"Bernard Bouvier--. Los amarillentos folios con las esquinas de muchas de sus páginas desgastadas dejando fragmentos de papel en los dedos no solo son testigos de los años que tiene la copia que adquirí, pero sospecho que también de la falta de cuidado de los anteriores propietarios. El exlibris muestra que ha pertenecido a la Llyfrgell Library de la Prifysgol Bangor University en el Norte del país de Gales; luego de ser descartado por esa biblioteca me pregunto cuántos cambios de manos tuvo antes de finalizar en $\mathrm{Ca}$ mille Sourget. Pero, debo resistir lo que mi bibliofilia me conduce a escribir y recordar que me prometí no registrar lo baladí.

En mi búsqueda de lo publicado sobre Amiel, el haber leído los comentarios en el Revue des sciences philosophiques et théologiques me despertó interés a leer la tesis de Bopp; en el número 2 del volumen 2I, el Revue dice:

Le mérite de L. Bopp est d'avoir suivi docilement la pensée d'Amiel dans toutes ses nuances, ses retours, ses beautés et ses ombres; il en a expliqué le caractère éminemment fluide et déconcertant par le tempérament de l'homme et les influences subies; 
cette méthode assure à son ouvrage une valeur objective et des conclusions qui demeureront. (Revue des sciences philosophiques et théologiques, 1932 : 57).

Abril, final del mes.

Retornando a mis clases, a menudo lo repetitivo de mi tarea docente me exaspera, y estoy tratando de encontrar cierta fortaleza en la rutina de la enseñanza. Progresivamente he llegado a comprender que "ninguna actividad sistematizada y repetida influye en la psicología y luego en la vida entera tan hondamente como la rutina de enseñar" (Marañón, 1932: 24). Si bien no tengo la libertad de ser lo que Marañón llama "un maestro libre", que "enseña elásticamente, lo que quiere y a quien quiere", puedo enseñar como quiero; son los beneficios de la a menudo abusada libertad de cátedra. Ya desde hace tiempo he aceptado que las clases que imparto no son, como generosamente las universidades las llaman, "clases magistrales" sino expositivas que relatan fundamentalmente lo que los estudiantes pueden encontrar por si mismos, a pesar de que gradualmente he comenzado a incluir en mis clases conceptos integradores del conocimiento que a veces se encuentran dispersos; pero aún estoy lejos de poder llamar a mis clases magistrales. Cuando leo mis notas en preparación para las clases, resuena en mi mente lo que Amiel ha escrito en una entrada de su Journal intime del 22 de agosto de I849:

En relisant ma dissertation, je l'ai trouvée grossièrement écrite. Tout d'abord, il me faut plus de gravité, de modestie et d'autorité; j’ai à me faire homme et à dépouiller les allures imberbes de la phrase, les assertions tranchantes, les paradoxes d'adolescent, la fougue juvénile, qu'on tolère sans conséquence, Acquérir, par la pensé, la maturité et la forcé; par le style, la pureté et la goût. (Amiel, 2006: 113).

Me he esforzado en cambiar mi práctica docente guiado por el dictum de Marañón: "El verdadero maestro ha de saber con toda naturalidad saltar desde su púlpito profesoral al banco del oyente" (Juderías, 196o: I82), pero no estoy seguro si soy exitoso. El problema que veo en el "oyente" es que durante las clases se empeña en tomar notas y más notas, pero no creo que el esfuerzo está en comprender realmente lo que oye. No creo que como Amiel --según lo que dice Bopp-- sea capaz de entrar en "communion d'esprit" con los estudiantes y me pregunto si entre los estudiantes y yo aún nos separa el "doble abismo de la autoridad y el conocimiento".

Lo que ha escrito Amiel muestra que era muy escrupuloso en la preparación de sus clases. Tratando de organizarme mejor me interesé en leer las anotaciones que Amiel hizo en preparación de una de sus clases, 
Observations

Minutes

Vue intérieure du système scolaire.......................... 3

L'oevre scolaire, le maître....................................... I

L'oevre scolaire, la forme de l'enseignement............. 5

L'oevre scolaire, la matière ................................ IO

Education réciproque ..................................... IO

Education personnelle ................................... I2

Conclusion ................................................ 3

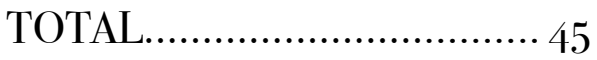

(Bopp, r926: 276)

Debo encontrar un punto de equilibrio entre la alta estructura de las clases de Amiel y una espontaneidad que no impresione a los alumnos como caos y por ello falta de preparación.

Inicio del mes de mayo.

La literatura sobre Amiel es bastante extensa, particularmente en referencia a su Journal intime y el análisis de su carácter y perfil afectivo ha sido motivo de extensa literatura. Lo escrito sobre Amiel va desde admiración, como la de Berthe Vadier (Carmagnola-Richard, I925), a la crítica destructiva como lo fue la opinión de Oscar Wilde; Clayworth y Small señalan que en un manuscrito de una obra no publicada, Oscar Wilde tras leer el diario de Amiel llega a la conclusión que él es un "psychological Narcissus" y su vida "the most tedious of all tragedies, a tragedy without a hero" (Clayworth \& Small, I996: 285). Pero, lo que no he podido encontrar con el detalle que desearía es un análisis de Amiel como docente.

Varias cátedras habían quedado vacantes en Ginebra y se supone que los artículos que Amiel había publicado en la Bibliothèque universelle influyeron para que él fuera considerado para ocupar la cátedra de estética y literatura francesa en la Academia, cátedra que anteriormente había ocupado el profesor Adolphe Pictet. Amiel escribió en la Bibliothèque un elogioso artículo sobre el libro de Pictet, Du beau dans la nature. En este artículo Amiel dice que,

...comme il arrive avec les hommes supérieurs, une chose le frappa plus encore que l'enseignement même, ce fut le maître. Aussi ce souvenir lui est resté bien doux, et pour ce double service, qui n'est pas de ceux qu'on oublie, l'étudiant d'alors se plaît à témoigner au professeur de 1840, sa sincère et filiale gratitude (Amiel, I856 : 439).

Encontré interesante que George Sand, que con frecuencia escribe con ingeniosa mordacidad sobre otros, expresa su alta opinión de Adolphe Pictet como persona. En la 
carta que Sand le escribe a Pictet el I ${ }^{\circ}$ de enero de i868, ella incluye: "vous êtes l'homme le plus indulgent, le plus délicat, le mieux disposé pour moi et le mieux élevé que je connaisse" (Sand, I964: 3I2); Sand firma esta carta Piffoël. George Sand y su hijo Maurice, ambos con narices prominentes, fueron bautizados por sus amigos Piffoël --derivación de pif--. Me entretuvo mucho el leer el ensayo de Sand, Entretiens journaliers avec le très docte et très habile docteur Piffoël, professeur de botanique et the psychologie. Particularmente en este momento está presente en mi mente lo que Sand ha escrito en el prefacio: "On ne fait un journal que quand les passions sont éteintes, ou qu'elles sont arrivées à l'état de pétrification qui permet de les explorer comme des montagnes d'où l'avalanche ne se détachera plus." (Sand, I97ı: 977).

Pero, volviendo a Amiel. El Io de abril de i849 el Conseil d'etat de Genève lo nombra profesor de estética y literatura francesa luego de haber pasado --_sufrido?-- una serie de pruebas: "'o La rédaction d'une thèse sur le mouvement littéraire dans la Suisse romane"; "2 Deux exposés oraux d'une demi-heure sur un sujet de littérature française et su un sujet d'esthétique"; "3o Trois leçons publiques, l'une sur l'esthétique et les deux autres sur la littérature française", sobre temas indicados a Amiel tres horas antes de que tuviera que dar las lecciones públicas. Estos temas fueron: diferencias entre el estilo de los escritores del siglo XVIII y los del XIX, características de la literatura del Imperio, y discurso sobre la belleza moral (Bopp, I926: 268). Posteriormente como la cátedra de filosofía quedó vacante, Amiel también fue nombrado, en forma interina para dar un curso de historia de la filosofía.

Mediados de mayo.

He pensado mucho en los concursos, particularmente porque me han anunciado que dentro de poco debo presentarme a un concurso de oposición. El establecer los concursos para plazas de profesores, intentó derrocar la nobleza académica de alta cuna y substituirla por un sistema de "meritocracia", pero el resultado es que este sistema con sus requisitos de certificaciones y títulos muy frecuentemente ha conducido a la promoción individual sin conferir una verdadera legitimidad académica. Marañón, en su discurso en la Real Academia de Ciencias Exactas, el 3 de diciembre de 1947 dijo: "La causa fundamental de los defectos de nuestro profesorado es clara como la luz del día. Reside en el modo de reclutarlo, en las bárbaras y anticuadas oposiciones, vergüenza y cáncer de la Universidad española." (Juderías, I960: I87). Marañón identifica cuatro "males" en el "método oposicionista" que deseo anotar para comentarlo con nuestra Rectora:

Primero, aun suponiendo una absoluta competencia y ecuanimidad en los jueces, los ejercicios de oposición no revelan ni pueden revelar el saber verdadero ni la eficacia pedagógica del aspirante, sino un conjunto de cualidades, como la memoria, la brillantez expositiva --la brillantez expositiva, que puede no ser la mejor técnica para enseñar--, la erudición improvisada e impresionante y la 
habilidad dialéctica, ninguna de cuyas cualidades es necesaria ni siquiera importante para el ejercicio magistral. [...] Segundo: la oposición elimina para la enseñanza un número importantísimo de posibles grandes maestros, incapaces de vencer al oposicionista aguerrido en los lances de la absurda prueba [...] Tercero: la oposición, al abrir la máxima puerta del profesorado mediante unas pruebas verbalistas que se pueden realizar en plena juventud, mejor dicho, que sólo en la juventud se pueden llevar a cabo con brillantez, elimina de la investigación y de la enseñanza a un número enorme de gentes aptas que tendrían que colaborar en la tarea pedagógica si a colaboración fuera, como es en todas partes, condición esencial para el acceso a la Cátedra. Cuarto: la técnica oposicionista tiene aún otro inconveniente, que parece banal y yo juzgo el peor: el que imprime, para siempre, en la cabeza de los opositores, que son la flor de cada generación por su ambición y su capacidad, la huella funesta del hecho de que para triunfar, más que el saber verdadero, se cotiza la exhibición verbal, el cientificismo. [...] muchas veces, conseguida la prebenda --que trae consigo la categoría oficial vitalicia, el éxito profesional y el paso a otras posibles sinecuras-- el triunfador se dice: ¿Para qué molestarse en rectificar un camino que me ha sido tan pingüe? (Juderías, I960: I88-I9I).

A menudo se me ha dicho que los concursos de oposición tienen su mérito, particularmente el evitar favoritismos. Marañón dijo que se han emitido argumentos para defender las oposiciones, y él considera que el peor es el siguiente: "En un país de favoritismos como el nuestro, resulta, con todos sus inconvenientes, la única garantía de justicia. Argumento recusable, empero, ante todo por dignidad nacional, porque presupone una corrupción en los encargados de juzgar que no podemos admitir y que, por fortuna, puede terminantemente denegarse" (Juderías, I960: I94).

En este discurso del año I947, Marañón se muestra optimista diciendo: "Las oposiciones desaparecerán, por honda que sea su raíz y por robustos que sean los intereses que las amparan. Tengo fe absoluta, por el bien de España, en que desaparecerán. Desaparecerán como desaparece todo lo que sirve mal a los intereses generales. Y sólo cuando hayan desaparecido comenzará la obra de reforma profunda del profesorado." (Juderías, I960: г96).

La profecía de Marañón no se ha cumplido; no solo las oposiciones han permanecido sino que se han robustecido, probablemente con la contribución de aquellos que pasaron por el sistema y que pensarán como dijo Marañón, “¿Para que molestarse en rectificar un camino que me ha sido tan pingüe?” Irónicamente este discurso de Marañón, con su profecía no cumplida precede a un ensayo titulado "Milagro". Con respecto a los exámenes y a los concursos de oposición Giner de los Ríos también expresa su opinión despectiva: 
En cuanto a los exámenes, concursos y oposiciones, parecen inventados, dice, por alguno que haya querido más bien atormentar que beneficiar a la humanidad, aplicando aquella errónea filosofía, antes mencionada, de que todo lo que es desagradable es útil, y que la acumulación (temporal y momentánea) de hechos constituye la verdadera sabiduría y da la exacta medida de la fuerza cerebral. Pero el más gran necio puede hacer el mejor examen; mientras que ningún hombre discreto puede siempre decir lo que sabe. (Giner de los Ríos, I96o: 73).

Para levantarme el ánimo voy a escribir algo más ligero sobre los concursos que Ella me contó. Su padre asistió a la fête du tabac un congreso de fumadores que la Ligue nationale pour la défense de les fumeurs llevaba a cabo anualmente. En este evento habían tres concursos: concours de vitesse (cigares), concours de lenteur (pipes) y concours de l'élégance du geste (cigarettes); su padre participó, sin éxito, en el concurso de pipas del congreso en Saint-Ouen. En el de cigarettes, de acuerdo a Le Matin participaron seis "charmantes fumeuses" que rivalizaron en la gracia del arte. El congreso finalizó con la elección de la reina del tabaco, Mlle Capoulade.

Aún en el mes de mayo

Ayer tuvimos la visita de la Rectora que nos comunicó que debida a la situación financiera de la universidad varios cursos perderán créditos. Esto mismo le sucedió a Amiel cuando en febrero de I85 I le cancelaron los créditos que gozaba la cátedra de estética. En una carta que del jefe del departamento se expresan las razones por la cancelación de los créditos: "Le nombre presque nul des étudiants qui suivent les cours d'esthétique prouve suffisamment que cette branche des connaissances philosophiques et littéraires parait avoir trop peu de faveur pour comporter une dépense hors de proportion avec le nombre de ceux qui en profitent." (Bopp, I926: 269). Amiel se dedica enteramente a la enseñanza de la filosofía resultando luego de tres años ser nombrado catedrático. Previamente, JulesErnest Naville ocupó esa cátedra desde I844 a I848. Amiel asistió a varias de las conferencias impartidas por Naville. El 28 de noviembre de I859 Naville imparte su primera conferencia sobre La vie éternelle y en su diario Amiel registra:

Ce soir, entendu Ernest Naville. C'était admirable de sûreté, de loyauté, de clarté et de noblesse. Il a prouvé que la question de l'autre vie devait être posée, malgré tout. Beauté de caractère, grande puissance de parole, grand sérieux de la pensée, voilà ce qui éclate dans cette improvisation qui est aussi serrée qu'une lecture et qui ne se détache presque pas de ses citations (Bossuet et Jouffroy) dont elle est entremêlée. C'est plus ferme et plus calme que Pressensé, moins oratoire, mais peut-être plus fort, car il n'y a rien du tout de théâtral. La grande salle du Casino était comble jusque dans l'escalier et l'on voyait pas mal de têtes blanches. (Amiel, I949: I3I) 
Como lo indica Amiel, esta conferencia estaba restringida a los hombres. Me parece interesante que posteriormente Naville publica sus discursos en L'Athénée de Genève bajo el título La condition sociale des femmes, donde dice,

L'amélioration de la condition sociale des femmes, et spécialement de leur condition civile et économique, est une cause excellente et digne de la chaude sympathie de tous les hommes de bonne volonté mais, je le répète, cette cause excellente risque d'être compromise par une erreur grave qui la discrédite. Cette erreur est l'oubli de la diversité naturelle des sexes qui appelle et justifie la diversité des fonctions. Je résumerai toutes les considérations quejai présentées à ce sujet dans un proverbe qui, sous une forme agricole et populaire, exprime une haute vérité "Que chacun fasse son métier, les vaches seront bien gardées"(Naville, I89г: I34).

Primera semana de junio.

Esta semana he vuelto a leer el Journal intime de Amiel en las dos ediciones que tengo en mi poder, ambas selecciones de las I7.ooo páginas que forman l'édition intégrale. Una de mis dos ediciones del diario de Amiel es esa expurgada que Marañón ha llamado una "biografía literaria" con la introducción de Edmond Scherer. La otra, con la introducción de Bernard Bouvier, es más completa y se la ha llamado "el testimonio de una vida”; en las palabras de Marañón una “biografía humana” (Marañón, r932: 39).

Al final de sus días, Amiel encomienda su diario a Marie-Françoise [Fanny] Mercier: "Vous m'avez dit quelquefois que vous étiez ma veuve. Je vous laisse des droits de veuve: ma correspondance et mon Journal" (Amiel, I949: 22). Bouvier relata que en el año I882 Fanny Mercier y él, un joven estudiante acuerdan solicitar a Edmond Scherer que patrocine la publicación de las partes del diario de Amiel que ella ha seleccionado. En la primavera de ese año, Bouvier visita a Scherer con una carta de presentación de Fanny Mercier y un "grande enveloppe jaune" conteniendo fragmentos del diario de Amiel que hizo Mercier. Scherer ni siquiera abrió el sobre con el manuscrito y le dijo: "Reprenez ces papiers, jeune homme, me dit-il. J'ai connu Amiel, et j'ai lu ses ouvrages. Rien ne lui a réussi. Laissons dormir sa mémoire. Ne remuons pas ses cendres". Bouvier insiste en que Scherer lea el manuscrito y le deja el voluminoso sobre amarillo. Evidentemente la lectura de esas páginas cuidadosamente seleccionadas fue persuasiva dado que al día siguiente Scherer le escribe a Fanny Mercier: "Envoyez-moi ce que vous pouvez du Journal..." (Amiel, I949: 25). En octubre del mismo año se publica la primera edición del diario de Amiel que contiene las páginas seleccionadas y también una extensa introducción de Scherer, la cual finaliza: "il n’a pas écrit ce Journal avec son talent, mais avec la substance de son âme, avec les palpitations de sa vie "(Amiel, I922: LXXVI). Scherer, que le dijo a Bouvier que había leído las obras de Amiel y no había nada en ellas, parece ser que cambió de opinión. Esto no debe asombrarme porque hay numerosos ejemplos de personajes del mundo literario --y por supuesto del mundo político-- que en distintos momentos expresan opiniones contradictorias. 
Mediados de junio.

Durante mi paseo por el bosque que rodea mi casa, estuve reflexionando sobre Amiel y ahora, de regreso deseo hacer algunas anotaciones.

En la serie Les cahiers romands el escritor y diplomático suizo René de Weck, en el prefacio a Amiel ou la noix creuse, cita a Marc Monnier: "car nous en avons assez, n'estce pas, d'entendre sonnera nos oreilles la sentence de Marc Monnier 'Le Suisse romand est un homme à qui l'Eternel a dit : 'Tu ne te débrouilleras pas!'"'(Weck, I93I: Io). Esta frase de Monnier ya ha sido citada por de Weck en su La vie littéraire dans la Suisse Française (I9I2), aunque precedida por un texto que es algo diferente: "Je ne puis songer à ces cent années de vie intellectuelle sans entendre siffler à mes oreilles cette boutade cinglante et vraie de Marc Monnier:.."(Weck, I9ı2: I6). El implacable sarcasmo utilizado por de Weck --nacido en Friburgo--no deja lugar a dudas de su opinión sobre sus compatriotas de habla francesa. En Amiel ou la noix creuse, edición de Les Cahiers Romands, se encuentran varios apéndices. El Appendice I que apareció en la Semaine littéraire (Genève) el I4 de enero de i922 se relaciona al breve comentario que de Weck escribió, en ocasión del centenario de Amiel, en el Mercure de France --del cual fue cronista por un cuarto de siglo--. Este comentario comienza relatando que: "Genève a célébré discrètement le centenaire d'Amiel. Louable discrétion."Y continúa con su ironie à bon compte: "Cet homme s'est fait un nom pour avoir su disjoindre et remonter avec la patience d'un horloger genevois la mécanique de sa vie intérieur." (Weck, I93I: I4-I5). La reacción a este comentario en la Semaine littéraire que aparece en el número del I 4 de enero de I922 es bastante fuerte y contiene frases como: "Il est bien regrettable pour la gloire du penseur de Genève que ses idées heurtent à ce point celles du critique fribourgeois"; "Elles ont, il faut le reconnaître, parfois une déplaisant odeur de fagot"(Weck, I931: 72). El segundo apéndice en Amiel ou la noix creuse es lo escrito por Alexis François originalmente publicado en la Semaine littéraire (Genève) el 28 de abril de I923, que comienza con un mordaz nadie-es-profeta-en-su-tierra: "C'est un fait, je crois, assez généralement vérifié, que les étrangers jugent notre littérature avec plus de bienveillance et the sympathie que nous ne le faisons nous-mémes quand nous voulons les instruire"(Weck, I93I: 73). Posteriormente, en este comentario François dice:

Le Mercure de France, comme on sait, a toujours abrité les évadés de la geôle romande. Ils sont un peu dans la situation de bannis que regardent de loin la terre ingrate dont ils se sont eux-mêmes exilés pour une raison ou pour une autre. De là leur visage triste, leur maintien sévère, et ce regard sans indulgence qu'ils promènent sur notre vie locale, notre art local, notre littérature locale. (Weck, I93I : 73-74).

François finaliza su comentario sobre los escritores suizos en forma metafórica: "Assez longtemps Cendrillon est restée au coin de son âtre. Il est temps de lui rapporter sur la coussin la pantoufle qu'elle a perdue, l'on ne sait trop comment, et que doit lui rendre son 
rang de princesse"(Weck, I93I: 75).

La respuesta de de Weck publicada en la sección Correspondance de la Semaine littéraire el I9 de mayo de I923 también es transcripta en Amiel ou la noix creuse, y como me esperaba salpicada de frases irónicas y referencias a François como "Mon honorable censeur": "J'ai commis un forfait plus horrible encore: dans un manuel scolaire d'inspiration catholique, pour le supplément qui traite de la Littérature française à l'étranger, j’ai écrit dix pages sur la Suisse normande."(Weck, I93I : 79). El contexto a esta frase de de Weck es que François se ha referido a la poca mención y, "apparemment sans enthousiasme", que aquel, ha hecho de la literatura suiza de lengua romance en su artículo Littérature française à l'étranger. También François menciona "des valeurs protestantes"; imagino que esto también se relaciona a la influencia del Calvinismo descrita por Amiel en l'édition intégrale:

Le Calvinisme a été pendant deux siècles l'âme de la Suisse romane; il a fait sa gloire, le substance de toute son activité, le centre de sa législation, de sa littérature, de sa diplomatie, de sa morale, de sa religion; le noeud de ses relations avec tout les coins de l'Europe: en un mot, à l'intérieur et à l'extérieur, il a été le foyer vivifiant et rayonnant de lumière et de chaleur, le principe vital imposant sa forme et son sens à tout. (Amiel, 2006: IOI).

En su respuesta a François, de Weck menciona que "jäai de bons amis protestants" (Weck, I93I: 80). El uso de esta frase defensiva de no discriminación ("algunos de mis mejores amigos son $X^{\prime)}$, como prueba de la ausencia de discriminación contra el grupo $\mathrm{X}$, se puede interpretar como ipso facto evidencia de lo contrario.

Aún en el mes de junio.

He estado meditando sobre estas escaramuzas entre escritores que siempre me han entretenido. En la introducción al Essais critiques, Bouvier cita a Amiel que hace referencia a lo escrito por Scherer sobre los Dialogues philosophiques de Renan: "La critique d'un critique par un critique est extrêmement curieuse." "Edmond Scherer es très fort, mais je lui voudrais un peu plus d'objectivité et un peu plus de vénération. Son acide sulfurique dissout même le cristal ou le platine de son propre flacon"(Amiel, 2006: 55). En sus Pensées Amiel dice que "La critique consciencieux a d'abord à se critiquer lui méme: ce qu'on ne comprend pas, on n'a pas le droit de le juger" (Amiel, I854: I80).

Reconozco que a mi no me ha sido fácil hacer una autocrítica genuina --no identificar debilidades que se convertían en fortalezas, como "tengo demasiada pasión por el trabajo", "soy un perfeccionista", etc.-- lo cual no me ha inhibido en criticar severamente el comportamiento de otros. La cita de Amiel hecha por Bouvier me ha ayudado a resumir lo que debo tener presente con respecto a la crítica:

La bonne critique est celle qui collabore avec l'oeuvre, qui suscite, suggère des idées, aime, élève, fortifie le producteur; qui couve le talent et le développe en le 
redressant au besoin. La bonne critique est maternelle, c'est-à-dire sympathique, encourageante, excitatrice, en même temps que clairvoyante. (Amiel, 2006 : I9).

Me apetece mucho su estilo más metafórico: "la critique n’est ni une science ni un art, c'est un oiseux et frivole caquetage, insupportable comme l'impertinence babillarde, stérile comme l'exercice de deux vanités, indigne en tour cas de l'attitude d'un esprit sérieux" (Amiel, 2006: 23).

Debo decir que yo he leído el diario de Amiel con sumo decoro; como indica Marañón en el prólogo del estudio sobre Un estudio sobre la timidez:

las cosas, en su aspecto moral, no son casi nunca buenas o malas en absoluto; y que su eficacia negativa o positiva depende, en su mayor proporción, del oído que las escucha que de los labios que las pronunciaron. Cuando se oye decorosamente, no hay nada que no sea limpio. (Marañón, I932: XII).

Y además lo he leído con un "piadoso respeto", "porque la piedad hacia él [Amiel] es en cierto modo piedad hacia nosotros mismos y comprensión de aquella parte de nuestra conciencia que no tenemos el coraje de enseñar” (Marañón, I932: 35-36).

He pensado en registrar algunos comentarios sobre los comentarios que, tanto en sus entradas en el diario como en otros escritos, Amiel hace sobre el calvinismo.

En la entrada al diario hecha en Berlin el I5 de noviembre de I848, Amiel ha escrito:

La vie calviniste... attention, tu touches là le point brúlant. Si l'élément fondamental et caractéristique de la nationalité genevoise est le protestantisme, ce n'est que dan une révolution du protestantisme, c'est-a-dire une restauration ou une métamorphose que le rajeunissement de Genève est possible. La Genève nouvelle ne peut plus être l'ancienne. Quelle sera sa religion? son principe? -- Pas de rêverie ! C'est toujours sur les frontières des religions que se rencontre l'intolérance; le besoin de conservations rend l'attitude plus polémique. Espérer une conciliation du catholicisme et du protestantisme à Genève serait s’abuser. (Amiel, I949 :43)

Posteriormente, en su ensayo L'Académie de Genève, --fundada por Calvin el 5 de junio de I559-- Amiel reitera sus reflexiones sobre el Calvinismo y la iglesia ginebrina (Amiel, 2006: 2OI-2I4).

Amiel inicia su poema A ma fenêtre, con su característico espíritu melancólico, "Cielbleu. Temps frais. Air pur. Vague mélancolie" y con este tono hace breve referencia al austero Calvin, "Sous mes yeux, le vieux mur tout criblé de fenêtres / Du collège élevé par l'austère Calvin; / Par delà ces hauts toìts qui parlent des ancêtres, / Rumeurs de la cité... Que tout est vide et vain" (Amiel, I880: II6). 
Julio, mes de vacaciones.

Aunque el diario de Amiel es a menudo repetitivo me atrae porque además del examen de conciencia que él hace, me fascina la espiritualidad que genera, particularmente la narrativa de sus solitarios paseos:

Quelle jolie promenade! ciel pur, soleil levant, tous les tons vifs, tous les contours nets, sauf le lac doucement brumeux et infini. Un oeil de gelée blanche poudrait les prairies, donnait aux haies de buis vert une vivacité charmante et a tout le paysage une nuance de sante vigoureuse, de jeunesse et de fraicheur (Amiel, 1949: 54). Promenade d'une demi-heure aujardin par une fine pluie... nature mélancolique, les feuilles tombaient de tous côtés comme les dernières illusions de la jeunesse sous les larmes de chagrin incurables (Amiel, I949: 75).

Como una muestra de la habilidad que tiene Amiel para describir el placer que le causa lo que a otros nos pasa desapercibido debo registrar --aunque sea extenso-- lo que él escribió sobre la niebla:

Le brouillard a certainement sa poésie, sa grâce intime, son charme rêveur. Il fait pour le jour ce que la lampe fait pour la nuit; il pousse l'esprit au recueillement, il replie l'âme sur elle-même. Le soleil nous répand dans la nature, nous disperse et nous dissipe; la brume nous rassemble et nous concentre, elle est donc cordiale, domestique, attendrissante. La poésie du soleil tient de l'épopée; celle du brouillard tient de l'hymne élégiaque ou du chant religieux. Le panthéisme est fils de la lumière; le brouillard engendre la foi aux protecteurs prochains. Quand le monde universel se ferme, la maison devient le petit univers. Dans l'éternelle vapeur on s'aime mieux, car la seule réalité alors c'est la famille, et dans la famille, le cour. L'action du brouillard est donc analogue à l'effet de la cécité, et l'action du soleil a l'effet de la surdité; car l'homme de l'oreille est plus tendre et plus sympathique; l'homme de l'oeil est plus sec et plus dur. Pourquoi? parce que l'un vit surtout de la vie humaine et intérieure, l'autre surtout de la vie naturelle et extérieure. (Amiel, I949: г9I).

El diario de Amiel posee algunos de los defectos, pero también muchas de las virtudes que él atribuye a Joseph Joubert en referencia a sus Pensées: "c'est un penseur plutôt qu'un philosophe"; "c'est un philosophe et un artiste imparfaits plutôt que manqués"; "c'est un entomologiste, un lapidaire, un joaillier, un monnayeur de sentences, d'adages, d'aperçus, d'aphorismes"(Amiel, r949: 5).

He encontrado en el diario de Amiel mucho de lo que yo sentía pero no encontraba la manera de expresarlo. Sin embargo, al registrar lo que siento debo recordar que "el narrar nuestras experiencias puede llegar a atormentarnos. Sin embargo, lo que nos 
atormenta no son las imágenes o palabras, sino la naturaleza de la propia experiencia que está detrás de la narrativa" (Branda, 2OII).

El escribir siempre me ha permitido organizar mis ideas; a diferencia de las epístolas no habiendo un destinatario no siento la necesidad de extrema claridad. Además, el mantener un diario es una manera de obtener una perspectiva del progreso de mis ideas, que reconozco es un proceso egocéntrico --dominante en el diario de Amiel quien fue una influencia en mi decisión de mantener un diario y registrar mis observaciones a pesar de que un diario es "una vanidad o un anacronismo: la ficción de que nuestra vida importa" (Vásquez, 20I1: 66)--.

Recordando las promenades de Amiel y como todavía hay un poco de sol, voy a hacer una breve caminata en el sendero que cruza el bosque cerca de donde vivo.

Última semana de agosto.

No me he sentido con ánimo de hacer entradas en mi diario durante el verano. Me he dedicado a preparar las clases para el curso que va a comenzar.

Habiendo finalizado de leer Amiel o la incapacidad de amar, el libro que escribió José de la Luz León, (I927) --del cual no me debo olvidar de hacer algunas anotaciones-- recordé que en la copia de Perto do coração, que Ella me dio estaba subrayado lo que la protagonista dice: "liberta do medo de não amar...Medo de não amar, pior do que o medo de não ser amado"(Lispector, I995: Io8).

Cuando comencé a leer la novela de Juan Gabriel Vásquez, El ruido de las cosas al caer, encontré una frase que penosamente me puso de manifiesto lo que de mi memoria de Ella me atormenta. Su recuerdo es como un "fantasma fiel y dedicado, presente siempre, su figura de pie junto a mi cama en las horas de sueño, mirándome desde lejos en las de la vigilia” (Vásquez, 2OII: I4).

Mediados de septiembre.

El retornar a la universidad me genera una sensación extraña donde me siento en el interior de un espacio que a veces es real y a veces imaginario. Lo que estoy viviendo en la facultad a veces me parece un mal sueño del cual en cualquier momento me voy a despertar.

Cuando con Ella hice el curso sobre el "realismo mágico" leímos los cuentos de Julio Cortázar. Recuerdo que en La noche boca arriba, Cortázar relata el accidente de un motociclista y las pesadillas que tuvo durante su estadía en el hospital. En las pesadillas era perseguido a través de la selva por aztecas que lo iban a sacrificar. En el cuento el protagonista va de un lado para el otro mezclando su pesadilla con ocurrencias en el hospital, sintiendo en un momento miedo y el otro alivio sabiendo que es una pesadilla, y que se va a despertar en cualquier momento y todo el sufrimiento se acabará. Pero, al final, a pesar del deseo y la esperanza de que cuando abriera los párpados la pesadilla de verse 
sacrificado por sus perseguidores desaparecería, se da cuenta que la persecución no es un sueño sino la realidad, y que el sueño fue el del accidente en la moto. La persecución estaba en el epígrafe del cuento: "Y salían en ciertas épocas a cazar enemigos; le llamaban la guerra florida" (Cortázar, I995: I59-I82).

Cuando veo la oposición a los cambios que se suponen mejoran la docencia pienso que me voy a despertar y darme cuenta que todo era una pesadilla. Pero, como en el cuento de Cortázar, la pesadilla es la realidad. Lo que fueron solo sueños era la docencia en un programa en el cual el aprendizaje auto-dirigido, centrado en el estudiante es lo principal, eso que yo creía que era la realidad. La campaña que llevan a cabo los profesores numerarios de adoctrinar a los docentes para que se unan a las huestes de los opositores al cambio es como la "guerra florida" que organizaban los aztecas para conseguir esclavos; a los que no se sometían se les perseguía, y cuando capturados se les ponía sobre el altar de sacrificio.

Lamento hacer estas anotaciones melodramáticas, pero realmente me siento agobiado. Creo que estoy enfrentando una disyuntiva. Debo, como se me ha aconsejado, hacer lo mejor que puedo en lo que tengo control y no preocuparme del resto o bregar por lo que se puede mejorar en la institución para ser fiel a su misión con el riesgo de generar más antagonismo.

Final del mes de septiembre.

Aunque no serán epístolas para Ella, no debo dejar de seguir escribiendo sobre lo que siento. Pietro Bembo, en Gli Asolani, pregunta si nuestras emociones dispares, esas grandes contrariedades, "cotante disuguaglianza", no son más fácilmente recogidas en escribir coplas que en el corazón: "né pure di fuoco solamente, ma di ghiaccio insieme et di quelle cotante disuguaglianza, le quali più di leggiero nelle rime s'accozzano che nel cuore?"(Bembo, I990: 228) dando a la pluma ocasiones muy nuevas y muy inauditas.

Durante todos los años en que hemos estado juntos, en ningún momento Ella ha hecho preguntas sobre mi vida antes de conocerla. No he interpretado esto ser falta de interés sino respeto sobre lo que yo mantenía en silencio. No voy llenar mi diario con datos autobiográficos sino referirme más que a los hechos del pasado, a su motivación y consecuencias. Nunca pude jactarme de ser feliz, quizás por temor de lo que me deparaba "el mazo del cielo" al que se hace referencia en La nave de los necios; tenía temor de ser, como lo ilustra Durero en el grabado en mi copia del libro, un necio que asoma su cabeza a la ventana impertérrito a pesar de que las llamas están devorando la planta baja de su casa (Brant, I998: I46). Ahora me siento lo suficientemente tranquilo, casi apacible y me siento con fuerzas para analizar los componentes de mi pasado. 
Al día siguiente.

Anoche no pude conciliar el sueño hasta entrada la madrugada, justo cuando dicen que los sueños se convierten en realidad. Como hoy es feriado me dedicaré a lo que me había prometido registrar del pasado.

A pesar de haber sido criado dentro de la fe católica --o quizás como resultado de ello-- en mis años adolescentes se despertó en mi una "curiosidad sacrílega”. Esto fue más que curiosidad excesiva, fue un Fürwitz faustiano que perturbó a mis maestros, pero lo que me proponía era tratar de conocer mejor aquello que mi razón no me permitía comprender y que se me decía que no era permitido hacer escrutinio de los "misterios divinos", aquellos que era suficiente que estuvieran en las Sagradas Escrituras para aceptarlos como verdaderos.

Mis maestros en el colegio religioso del que yo era alumno culpaban de mis desvíos a mi padre --originario de un estado totalmente laico-- ya que él no era creyente aunque no estaba opuesto a una enseñanza que no fuera laica. Sin embargo, sus ideas eran distintas de las de mi madre, que era una ferviente católica nacida en "Castilla La Vieja” --como ella decía con orgullo y lamentando que, con el Estatuto de Autonomía, esta región hubiera perdido su identidad--. Pero yo deseo eximir de toda culpa a mis padres que creo que lo único que deseaban era velar por mi bienestar.

Mis maestros religiosos decían que como Fausto yo tenía la osadía de "ceñirme alas de águila” y que esto me destinaba a que me sucediera lo mismo que a él. Yo sólo deseaba ser como aquellos que en la búsqueda de la verdad, como dice la Biblia, "se remontarán con alas como las águilas, correrán, y no se fatigarán; andarán, y no se cansarán” (Isaías 4O:3I). Yo expresaba claramente mi insatisfacción con las habituales explicaciones que recibía, y que no solo no explicaban nada sino que aumentaban mi tendencia a dudar tan intensamente, que a veces reconozco que rechazaba indiscriminadamente todo lo que no parecía responder a mis preguntas. Mis maestros decían que eran los espíritus diabólicos los que me infundían osadía en mis pensamientos y la insolencia de mis ansias de saber en lugar de tener fe. Yo me sentía inadaptado moralmente al entorno --moralmente no en el sentido ético de lo que es bueno o malo, sino en un sentido más amplio refiriéndome a aquello que realmente es importante para cada uno de nosotros--.

Por un lado sentía la imperiosa necesidad de lo concreto y lo verificable, the hard facts; por otro lado, me atraía intelectualmente lo abstracto y lo impalpable, pero las respuestas teológicas y metafísicas a mis cuestiones --que las planteaba con "el ímpetu un tanto petulante de la juventud"-- no las encontraba satisfactorias. Me decían --con cierto paternalismo-- que es natural que todos los jóvenes se preocupen por esos problemas: qué es el amor, el bien, el mal y cuál es la finalidad de nuestra existencia. Yo también me preguntaba si, además de la felicidad que me decían me esperaba en la otra vida, podía ser dichoso y disfrutar de ésta; me decían que aunque no creyera en la otra vida, el camino de la virtud sería el que me daría más felicidad en esta. De manera enfática se me aclaró que, como es la naturaleza humana, no sería posible que yo fuera siempre virtuoso o justo, y 
por ello no tendría derecho a no sufrir y debería soportar mi parte de las miserias humanas. Aunque fuera a ser un hombre justo, en mi calidad de hombre, iba a estar sujeto a los males de la humanidad y por lo tanto sin derecho a quejarme.

Hasta ese momento mi experiencia religiosa me había inculcado sin ninguna duda que mi destino en la otra vida era ir al purgatorio; mis maestros religiosos me habían dejado bien claro que esto es lo que le espera al hombre que se desviará de un sendero virtuoso debido a su condición de hombre. Recuerdo que cuando niño en la iglesia nos daban unas estampas religiosas que al reverso tenían una oración, que si se la rezaba otorgaban la gracia de descontar un cierto número de días de la dada por hecho estadía en el purgatorio.

El conflicto que me af ligía era la dualidad de mis sentimientos y la continua batalla entre lo que me demandaba la razón y aquello que era más abstracto y más espontáneo, eso que es espiritual, pero realmente sentido. Leí a Tolstoi cuando era un chaval y lo disfruté por las aventuras que narraba no por el significado filosófico de sus palabras que luego comencé a comprender. En el epílogo a la Guerra y paz, Tolstoi dice que admitir que en tanto creemos que la vida humana pueda ser dirigida por la razón, destruye la posibilidad misma de la vida (Tolstoy, I972: I22I). La observación de que "las hojas de un árbol nos deleitan más que las raíces” fueron para mí una inspiración para insistir en encontrar respuestas y apartarme de la visión superficial que estaba adquiriendo del mundo sin tener en cuenta lo que no es tan aparente, pero esencial.

¿Cuáles eran mis opciones? ¿Aceptar un sistema teocrático o ser nihilista? Años después leí el análisis que hace Albert Sorel de Joseph de Maistre y de Tolstoi; ese historiador francés considera al primero un teócrata y al último un nihilista, pero a ambos místicos. Isaiah Berlin cita a una conferencia de Sorel sobre Tolstoi publicada en el Revue Bleue en 1988: "The distance from the theocrat to the mystic, and from the mystic to the nihilist, is smaller tan that from the butterfly to the larva, from the larva to the chrysalis, from the chrysalis to the butterfly" (Berlin, I992: 56). Aunque yo no la pude encontrar en el texto de la conferencia que Sorel impartió en la Ecole des Sciences Politiques--que es la referencia de Berlin-- esta analogía me hizo sentir algo más tranquilo, pero más meditativo.

En una tentativa de enderezar el camino torcido y tortuoso que yo había elegido, me enviaron a hacer ejercicios espirituales con los jesuitas. Esto no tuvo el resultado que ellos esperaban, ya que en esos ejercicios conocí a un misionario y médico que en lugar de disuadirme, reafirmó mi necesidad de buscar respuestas y encontrar maneras de satisfacer mi curiosidad, no a través del dogma religioso sino a través de la acción. Este religioso me dijo que como le ocurría a Anteo recobraría la fortaleza que necesitaba para ser exitoso solo en cuanto mantuviera los pies sobre la tierra, dado que uno es más débil cuando se está inmerso en ideas etéreas, y que podría utilizar esa fortaleza en forma más edificante que la del gigante de la mitología griega. Debería aceptar que el mundo real es ocuparse de esas realidades económicas, sociales y políticas que constituyen nuestra vida cotidiana, y que carecen de glamour. Así fue como decidí seguir una carrera en medicina, 
con la esperanza de poder sanar --a otros, y a mí mismo espiritualmente-- y obtener respuestas a las muchas cuestiones que me abrumaban; no debería esperar a un estro divino sino concentrarme en la observación de los hechos, que aunque fuera imperfecta, me permitiría llegar a obtener más comprensión de la realidad.

Al igual que el joven adolescente Törless de Musil, aunque podía distinguir entre el día y la noche, mi problema estaba firmemente arraigado y no podía liberarme de él; en la noche parecían surgir de todos los rincones del dormitorio formas amenazadoras; en el día, a la luz del sol los muebles volvían a adquirir sus dimensiones normales; "lo hostil y el destino". Aunque a diferencia del estudiante Törless no fui cómplice en los actos de crueldad que ocurrieron en su instituto, yo también podía reconocer entre el día y la noche; pero como él dice, los hombres están rodeados de tenues fronteras que fácilmente pueden desaparecer, y los febriles sueños que rondan el alma pueden llegar a corroer los firmes muros que nos protegen cuando vamos a la busca de los motivos que expliquen nuestro inexplicable comportamiento:

Pero a Törless le quedaba todavía un ligero, un sutil cansancio. Ahora sabía distinguir entre el día y la noche. Y el caso es que siempre había sabido hacerlo, sólo que una pesadilla se le había filtrado, borrosa, a través de esa frontera, y se avergonzaba de tal confusión; mas el recuerdo de que podía ser otra cosa, de que hay alrededor de los hombres tenues fronteras que fácilmente pueden deshacerse, de que febriles sueños rondan el alma, corroen los firmes muros y abren de pronto inquietantes, trágicas calles...También este recuerdo se le había grabado profundamente y proyectaba pálidas sombras (Musil,I984:2I2).

José de Maistre, sobre el cual los jesuitas tuvieron una importante influencia constituye un ejemplo de lo difícil que siempre ha sido resolver el conflicto que se me planteaba. Maistre fue descrito en forma contradictoria por los polos sociales de su época. Los conservadores lo consideraban un corajudo paladín de la doctrina que ellos deseaban promover, los liberales como un abominable sobreviviente de una generación insensible. Pero en la segunda velada de San Petersburgo Maistre, de forma muy clara, aunque quizás demasiado agresiva y cortante, manifiesta lo que él consideraba agobiante en el hombre que

no sabe lo que quiere; quiere lo que no quiere, y no quiere lo que quiere; quisiera querer. Ve en sí mismo cierta cosa que no es él, y que es más fuerte que él. El sabio resiste y exclama “¿Quién me librará?” (Rom. VII, 24) El insensato obedece, y llama felicidad a su cobardía; pero no puede deshacerse de esa otra voluntad incorruptible en su esencia, aunque haya perdido su imperio (Maistre, I966: 36 ).

La duda y el cambio, tanto en nosotros mismos como en nuestro entorno, le da a nuestro vivir una incómoda --y a menudo-- peligrosa precariedad. La religión se considera superior a la razón --Maistre argumentaba-- no porque es capaz de proporcionar 
respuestas convincentes al tipo de duda que me agobiaba, sino porque no da ninguna respuesta; no argumenta ni trata de persuadir; la religión exige y considera que la fe es fe cuando es ciega, y no requiere ninguna justificación.

Cuando Don Iñigo de Oñaz, luego conocido como San Ignacio de Loyola, estaba recuperándose de sus heridas recibidas como soldado, leyó el Flos Santurum --la Legenda Sanctorum o Legenda Aurea que Ella me mencionó hace años en relación a San Bernardo-- lo que lo estimuló a seguir una carrera religiosa. Traigo esto a colación porque Iñigo de Oñaz tuvo que enfrentarse a serios dilemas; se dice que cuando pensaba en cosas divinas se sentía exultado, pero cuando a su mente acudían cosas mundanas, como corte, mujeres, buena vida, se sentía desconcertado y descontento. Esta duplicidad de sentimientos desapareció cuando, en la cueva de Manresa --donde escribió los Ejercicios espirituales-- tuvo varias experiencias místicas y raptos espirituales incluyendo una aparición de la Virgen que le disiparon todas las dudas y lo encarrilaron hacia un futuro religioso. Esto por supuesto es lo que él ha relatado desde que no ha habido testigos presenciales.

Yo, a menudo, he hecho un examen de conciencia que me ha llevado a aceptar lo que mi comportamiento tercamente rechazaba, que nada es blanco y negro. Ese examen de conciencia hace que, en los momentos en que me vanaglorio de mi mismo, encuentro en lo más hondo de mi corazón el nido de los odiosos reptiles de las malas intenciones; y en los momentos en que me siento descorazonado y disgustado conmigo mismo, puedo visualizar dentro de mi corazón el jardín luminoso de mis buenas intenciones.

Creo que ya he escrito lo suficiente; una caminata en el bosque me hará bien.

De regreso, al recoger la correspondencia que llegó ayer me encontré con una sorpresa que me ha dejado atónito; su primera carta desde que se fue de España. ¡Cuánto me alegró! Debo ignorar mi primera reacción de enfado conmigo mismo por la debilidad y la dependencia que significa el sentirme tan feliz al recibir su carta; no debo escatimar lo importante que para mí es tener noticias de Ella.

Oronte: L'espoir... C'est une dame, Qui, de quelque espérance, avait flatté ma flamme. L'espoir...

Alceste: Nous verrons bien!

Molière, Le misanthrope.

Nous verrons bien! 


\section{Referencias bibliográficas}

-Amiel, H.-F. (I854). Grains de mil, poésies et pensées. Paris: Cherbuliez.

- Amiel, H.-F. (1856). Du beau dans la Nature. L’art et la poésie. Études esthétiques par Adolphe Pictet. Bibliothèque Universelle de Genève. XXXII. Genève: Cherbuliez.

-Amiel, H.-F. (1880). Jour à jour. Poésies intimes. Paris: Fischbacher. Obtenido el 24 de noviembre de 20I6 desde: http://gallica.bnf.fr/ark:/I2I48/bpt6k5864938c.r=Amiel\%2C\%2O Henri-Fr\%C $3 \%$ Agd\%C3\%Agric

-Amiel, H.-F. (г919). Fragments d'un journal intime. Genève: Georg \& Co.

-Amiel, H.-F. (1922). Fragments d'un journal intime. Paris: Fischbacher.

-Amiel, H.-F. (1949). Fragments d'un journal intime. Paris: Delamain et Boutelleau.

- Amiel, H.-F. (2006). Essais critiques. Paris: Éditions du Sandre.

- Bembo, P. (1990). Gli Asolani/Los Asolanos. Barcelona: Bosch.

- Berlin, I. (1992). The hedgehog and the fox. An essay on Tolstoy's view of history. London: Orion Books.

- Bopp, L. (1926). H. F. Amiel. Essai sur sa pensée et sur son caractère. D’Apres Des Documents Inedits. Paris: Alcan.

- Branda, L. A. (2OII). El aprendizaje basado en problemas y la genuina realidad. Diario de un tutor. Educación Médica, I4, I5 I-I59.

- Branda, L. (20I5). Relaciones peligrosas - Un epistolario. Álabe 12. [www.revistaalabe. com] DOI: IO.I5645/Alabe.2OI5.I2.9.

- Branda, L. (20i6). Bridas al Corazón Salvaje. Epistolario. Álabe 14. [www.revistaalabe. com] DOI: Io.I5645/Alabe2or6.I4.9.

- Brant, S. (1998). La nave de los necios. Madrid: Akal.

- Carmagnola-Richard, J. (i925). Berthe Vadier et une correspondance inédite de H.-F. Amiel. Genève: H. Robert.

- Clayworth, A., Small, I. (1996). Amiel and Lord Beaconsfield: An Unpublished Review by Oscar Wilde. English Literature in Transition, I880-I92O, 39, 284-297. 
• Cortázar, J. (1995). Final del juego. Buenos Aires: Aguilar.

- Derrida, J. (1972) La dissémination. Paris: Seuil.

- Giner de los Ríos, F. (I990). Escritos sobre la universidad española. Madrid: Espasa-Calpe. Biblioteca Virtual Universal. Obtenido el 6 de octubre de $20 I 6$ desde: http://www.biblioteca.org.ar/libros/I54568.pdf

- Grossmith, G. Grossmith, W. (I995). The Diary of a Nobody. London: Penguin.

• Juderías, A. (I960). Idearium de Marañón. Madrid: Cultura clásica y moderna.

- Lispector, C. (1995). Perto do coração selvagem. Rio de Janeiro: Francisco Alves.

- Luz León, J. de la (ig27). Amiel o la incapacidad de amar. Madrid: Biblioteca Nueva.

- Maistre, de J. (ig66). Las veladas de San Petersburgo. Madrid: Espasa-Calpe.

- Marañón, G. (1932). Amiel. Un estudio sobre la timidez. Madrid: Espasa-Calpe.

- Musil, R. (1984). Las tribulaciones del estudiante Törtless. Barcelona: Seix Barral

- Naville, E. I89ı. La condition sociale des femmes. Lausanne: Arthur Imer.

- Revue des sciences philosophiques et théologiques. $193^{2}$ (p57).

- Sand, G. (1964). Correspondance (Mai 1837-Mars1840). Tome IV. Paris: Garnier Frères.

- Sand, G. (I97I). CEuvres autobiographiques. Tome II. Paris: Gallimard.

- Sand, G. (1883). Correspondance 1812-1876. Tome IV. Paris: Calmann Lévy.

- Tolstoy, L. (1972). War \& Peace. London: Pan Books.

-Vásquez, J. G. (2OII). El ruido de las cosas al caer. Barcelona: Alfaguara.

-Weck, R. de (1912). La vie littéraire dans la Suisse Française. Paris: Fontemoing.

-Weck, R. de (r93I). Amiel ou la noix creuse. Lausanne: Payot. 